\title{
Vibrotactile somatosensory stimulus to assist the transition from level walking to stair ascent in the elderly: a pilot study
}

Kiyoung Kwak', Seunghun $\mathrm{Ko}^{2}$ and Dongwook Kim ${ }^{1,3^{*}}$

From International Conference on Biomedical Engineering Innovation 2019

Kaohsiung, Taiwan. 15-19 November 2019

\begin{abstract}
Background: Although, in daily living, almost all stair ambulation is conducted posterior to level walking, or vice versa, there are only a few studies related to the transition compared to the studies on steady-state stair walking. Furthermore, neuromotor control in the instant of the transition is different from that of the steady-state stair walking. However, there are only a few studies investigating the transition from level walking to stair ascent in the elderly by comparing with young adults, and there is no study on the assistance of the transition movement in the elderly who are experiencing neurophysiological changes.

Thus, this pilot study aimed to compare the flat surface-to-stair ascent transition by the elderly to that seen in young adults, and to investigate how vibrotactile somatosensory stimulus (VSS), which has a positive effect on muscle performance and gait, affects the transition tasks in elderly people.

Results: In the first half of the stance phase, the elderly exhibited a higher moment and power of the hip extensor and a less moment and power of the knee extensor compared with young adults. In the second half of the stance phase, positive plantar-flexor power and support moment was higher in the elderly. In addition, during the singlelimb support phase, dorsiflexion was maintained in the elderly, whereas young adults appeared to have decreased dorsiflexion.

When the VSS was applied, the moment and power of the hip extensor, the plantar-flexor moment, and the support moment in the entire of the stance phase were increased. In addition, it was found that the degree of the kinetics parameters was different depending on the frequencies of the VSS.

Conclusions: This pilot study has revealed evident biomechanical differences between elderly people and young adults during the transition from level walking to stair ascent. Additionally, it has shown that the VSS may accentuate the features of the transition movement of the elderly and regulate joint kinetics. The results of the present pilot study can provide a base for further research and understanding of movement, which can be utilized in designing assistance aids for the elderly.
\end{abstract}

${ }^{*}$ Correspondence: biomed@jbnu.ac.kr

${ }^{1}$ Division of Biomedical Engineering, Jeonbuk National University, 567 Baekje-daero, Deokjin-gu, Jeonju-si, Jeollabuk-do, Republic of Korea

Full list of author information is available at the end of the article permits use, sharing, adaptation, distribution and reproduction in any medium or format, as long as you give appropriate credit to the original author(s) and the source, provide a link to the Creative Commons licence, and indicate if changes were made. The images or other third party material in this article are included in the article's Creative Commons licence, unless indicated otherwise in a credit line to the material. If material is not included in the article's Creative Commons licence and your intended use is not permitted by statutory regulation or exceeds the permitted use, you will need to obtain permission directly from the copyright holder. To view a copy of this licence, visit http://creativecommons.org/licenses/by/4.0/. The Creative Commons Public Domain Dedication waiver (http://creativeco mmons.org/publicdomain/zero/1.0/) applies to the data made available in this article, unless otherwise stated in a credit line to the data. 
Trial registration: CRIS, KCT0005434, Registered 25 September 2020, Retrospectively registered.

Keywords: Stair ascent, Somatosensory, Vibration, Elderly, Biomechanics, Level walking

\section{Background}

Ascending and descending the stairs is a more complicated movement than level walking, given the effect of gravity on the body and the specifications of the stairs. Hence, stair ambulation will be a challenging task for the elderly who experience neurophysiological changes, causing a decrease in muscle strength, reaction speed, and cognitive processing ability. For these reasons, stair negotiation by the elderly has been investigated by numerous studies and well documented [1-12].

In daily living, stair walking is mostly performed before or after level walking. However, participants in previous studies were asked to initiate walking the stairs from a static upright posture in front of the staircase. That is, former studies did not consider a realistic stair walking performed in daily living. In addition, most studies have focused on steady-state stair ascent and descent. Actually, we must face an instant of the transition from flat ground walking to stair ascent or descent.

It was reported that the transition requires adjustments in control of motion before the subjects set into a steadystate that continues over the following steps [7]. In other words, there will be another difference because the transition from level walking to stair walking, or vice versa, is accompanied by task recognition, gait strategy design for successful transition, and changes in movement modality. But, the transition is not fully investigated, while the steady-state stair walking has been much examined and well understood. Further, there are few studies to assist stair walking of the elderly.

There are a few studies investigated the transition from level walking to stair walking. Vallabhajosula et al. $[13,14]$ investigated the transition from level walking to stair climbing, and they reported the differences in joint kinetics (i.e., moment and power) between transition and steady state stair climb. However, the participants of their study were only young adults. Singhal et al. [15] investigated joint kinetics at the instant of transition from walking on flat ground to going down stairs for the elderly, but their results were about gender differences. Alcock et al. [16] reported that biomechanical differences between the 2-step transitioning and continuous stair ascent in older women. Carli et al. [17] compared only ground reaction force during the floor-to-stair transition gait in the elderly.

Although the transition movements are being investigated, the number of studies is limited compared to studies investigating steady-state stair ambulation. Moreover, there are no studies that have revealed the characteristics of the elderly by comparing it to that of young adults. To assist stair walking in the elderly who experience neurophysiological changes, it is important to reveal their characteristics in comparison with young adults. In addition, as mentioned earlier, the elderly experience neurophysiological weakness due to aging, and stair walking is a complex task. Therefore, a proof of concept study related to the support of stair walking for the elderly is needed. Hence, it is important to apply a means that can support and investigate its effect.

In this study, the transition from level walking to stair ascent was targeted, and vibrotactile somatosensory stimulus (VSS) was applied as a means of supporting during the transition movement. The VSS has been found to have various advantages through many studies. The VSS is the applying mechanical vibration to initially relaxed skeletal muscle or its tendon [18]. It was reported that involuntary enhancement of electromyogram (EMG) and muscle contraction strength is induced when mechanical vibration is applied [19]. Based on those results, positive influence of the VSS on muscle performance, strength, and power [20-23], effects on gait control [24, 25], and implications for rehabilitation [26] had been investigated. Therefore, the VSS could be utilized as a means to assist the transition from level walking to stair ascent of the elderly.

Thus, the present pilot study aimed to reveal the characteristics of level walking-to-stair ascent transition in the elderly by comparing it to young adults, and to investigate the effects of the VSS on the transition movement, and to discuss the VSS as a means to assist the transition movement.

\section{Methods}

\section{Participants}

To investigate the characteristics of transition movement in the elderly, young adults and older adults over 65 aged were recruited. A total of fifteen young adults (age: $25.5 \pm 1.5$ years old, height: $173.2 \pm 2.6 \mathrm{~cm}$, weight: $72.4 \pm 4.4 \mathrm{~kg}$ ) and ten elderly (age: $76.0 \pm 1.7$ years old, height: $166.7 \pm 3.7 \mathrm{~cm}$, weight: $68.0 \pm 5.5 \mathrm{~kg}$ ) participated in the study. Participants in the present study are the same as those in Peter et al., our previous study [27]. All participants had no musculoskeletal diseases, and were free from any neuro-physiological diseases, and could perform the level walking and stair climbing without any 
assistance. All participants provided written informed consent prior to conducting and participating in this study. The present study was approved by the Institutional Review Board of Jeonbuk National University (IRB File No. JBNU 2017-03-011-001).

\section{Vibrotactile somatosensory stimulus}

To apply the VSS during the transition movement, small linear actuators (DMJBRN0934AA, Samsung ElectroMechanics Co., Ltd., Korea) were attached to four targeted sites as follows: tibialis tendon, Achilles tendon, quadriceps femoris tendon, and biceps femoris tendon as shown in Fig. 1.

To regulate the frequency and intensity of the VSS, a function generator (AFG-2125, Good Will Instrument Co., Ltd., Taiwan) was used. In our previous studies [28, 29], the vibrotactile perception threshold in the range of $100 \mathrm{~Hz}$ to $300 \mathrm{~Hz}$, where the skin mechanoreceptor is sensitive [30], was measured. As a result, $190 \mathrm{~Hz}$ was most sensitive, $180 \mathrm{~Hz}$ was similar to $190 \mathrm{~Hz}$, and perception threshold rapidly increased at $200 \mathrm{~Hz}$. Based on these results, frequencies of $180 \mathrm{~Hz}, 190 \mathrm{~Hz}$, and $250 \mathrm{~Hz}$ were used in the present study so that the VSS conditions consisted of non-stimulus (NS, i.e., without the VSS), $180 \mathrm{~Hz}, 190 \mathrm{~Hz}$, and $250 \mathrm{~Hz}$.

The VSS intensity was $80 \%$ of the vibrotactile perception threshold. It has been reported that the response of the central nervous system appears below the perception threshold level [31,32], and that intensity upper perception threshold can cause discomfort or instability of postural balance [33, 34].

\section{Materials and instrumentation}

To capture the transition movement, a 3-D marker-based motion capture system, which is considered the standard method of movement analysis [35], was used. Infrared light-emitting diodes (Smart marker, Northern Digital Inc., Canada) were placed according to the motion module marker guide (MusculoGraphics, Inc., USA) as shown in Fig. 2.

A total of three position sensors (Optotrak Certus, Northern Digital Inc., Canada) and four force plates (Bertec Corp., USA) were used to record participants' movement and ground reaction force. Custom-built wooden staircase, as shown in Fig. 3, was used.

\section{Procedure}

All participants walked $3 \mathrm{~m}$ on a flat ground walkway at a self-selected speed before stair climbing, and then they continued to perform stair climbing without stopping. They completed a given task three times for each VSS condition. All the VSS conditions were applied randomly during the given task.

\section{Data analysis}

All kinematics (i.e. joint angle) and kinetics (i.e. joint moment and joint power) of the lower extremity joints (i.e. hip, knee, and ankle) were calculated using the software for Interactive Musculoskeletal Modeling (SIMM, MusculoGraphics Inc., USA), and support moment was calculated according to Winter [36]. Joint moment, support moment, and joint power were normalized to the participants' body weight, and the duration from

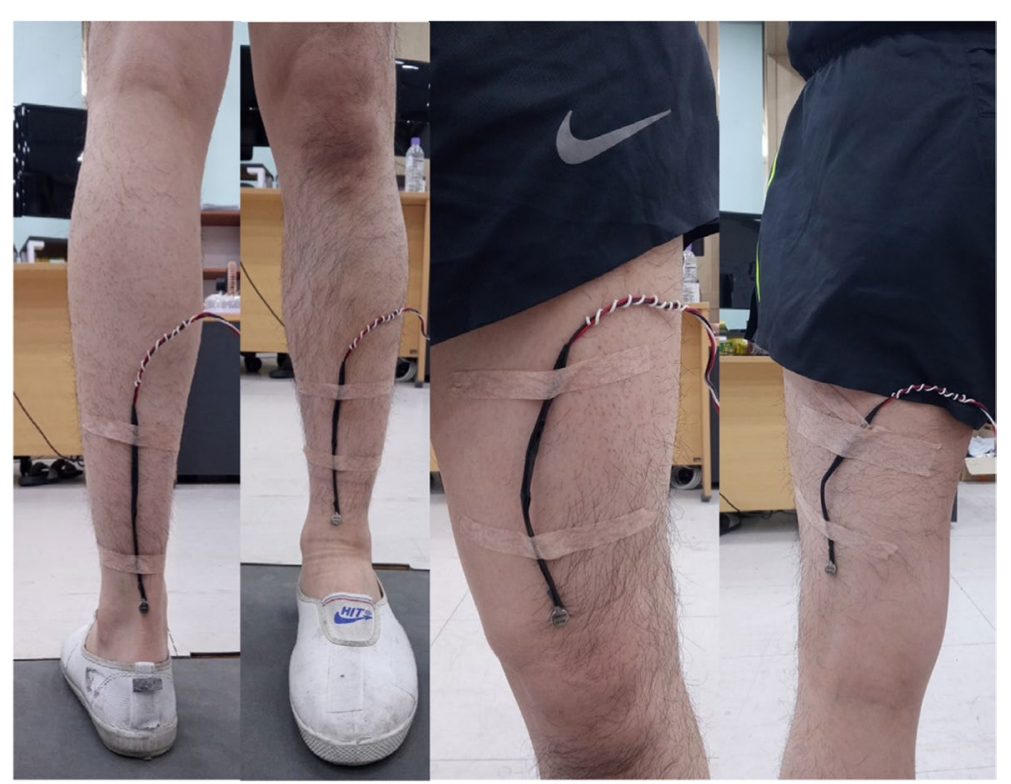

Fig. 1 Example of linear actuators attachment 


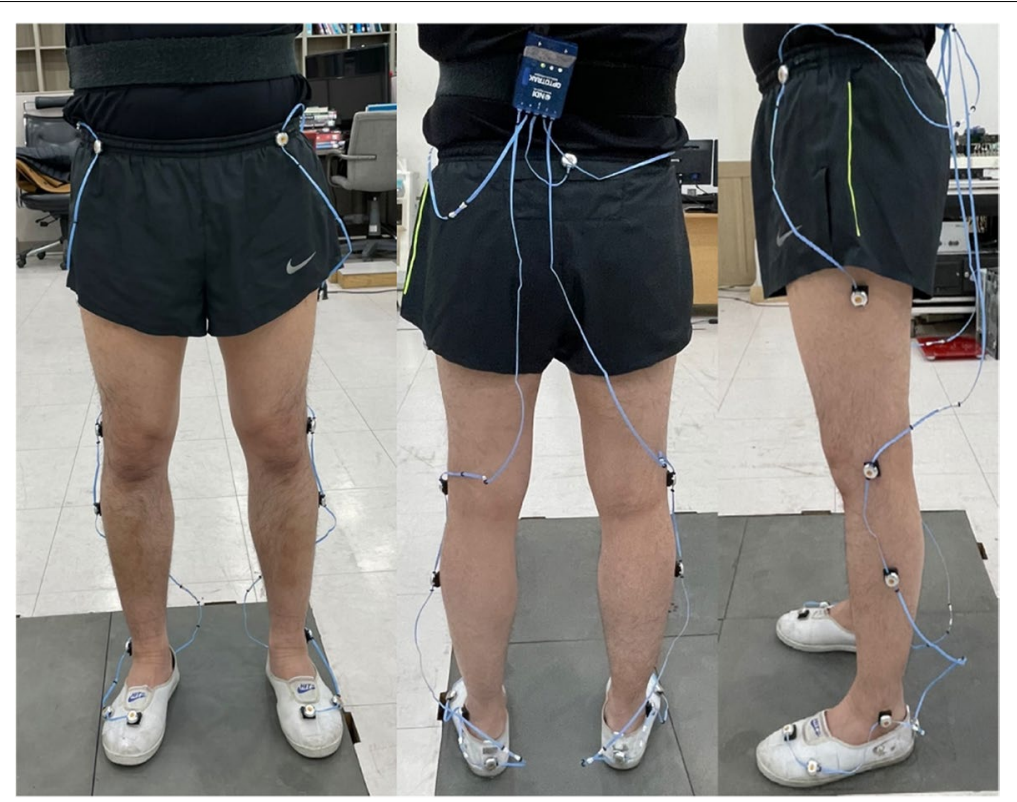

Fig. 2 Placement of infrared light-emitting diodes

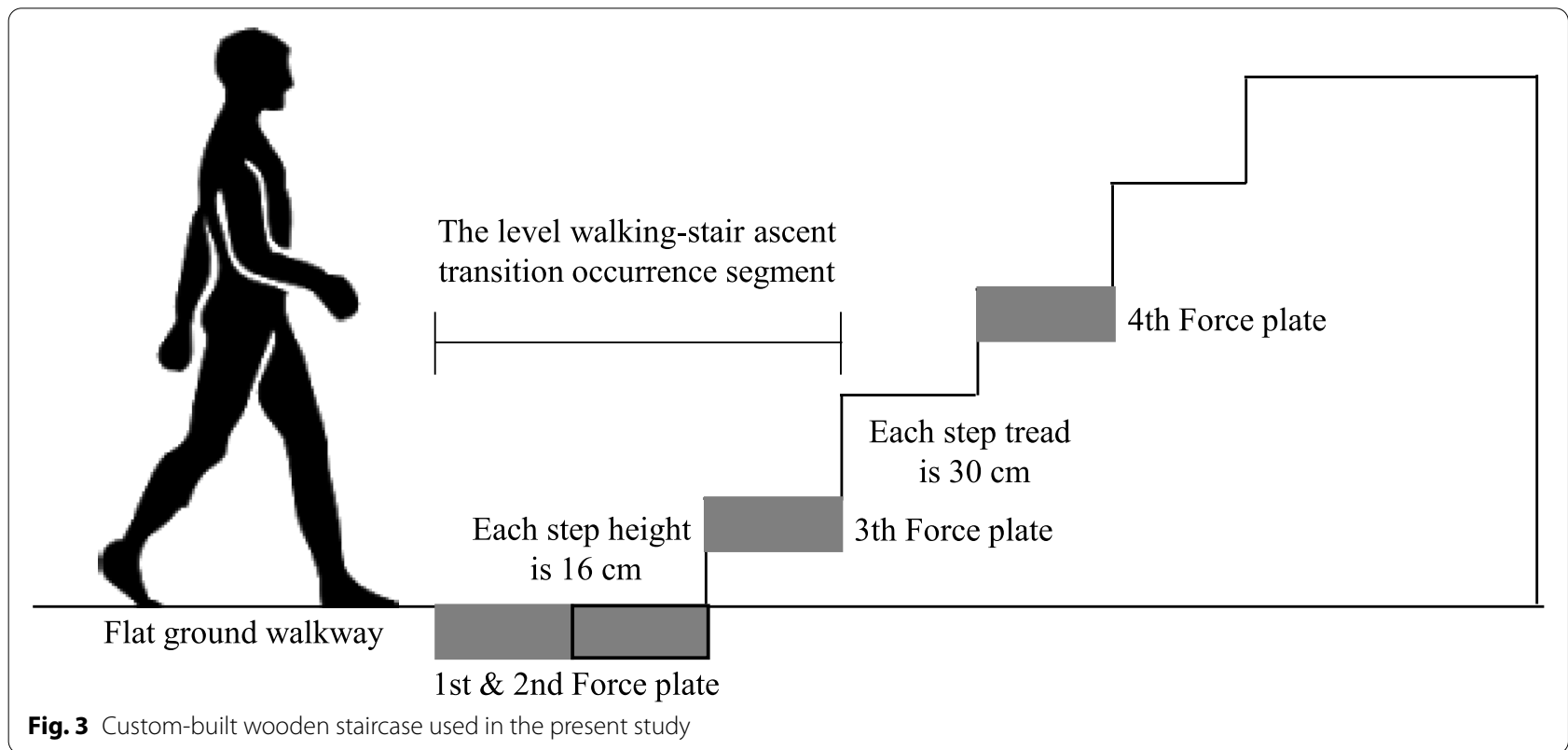

the toe-off to the toe-off of the ipsilateral leg was normalized from 0 to $100 \%$.

Profiles of joint angle, moment, and power for each participant derived during the three trials for each VSS condition were ensemble-averaged. Then, to derive a grand ensemble for the VSS conditions, ensemble-averaged profiles were ensemble averaged.
To examine the features of the transition movement of the elders, ensemble-averaged profiles are shown in Fig. 4. In addition, grand ensemble-averaged profiles are presented in Fig. 5 to investigate the effects of the VSS on the transition from level walking to stair ascent in the elderly. Peak joint angles, means of joint moment, support moment, and joint power in a specific period are 
presented in Tables 1, 2, 3 and 4 to determine the effects of the frequency of the VSS.

\section{Statistical analysis}

Peak joint angles, means of joint moment, support moment, and joint power were tested for normality using the Shapiro-Wilk test. Paired t-test and Wilcoxon signed rank test were used to test the effect difference between each frequency of the VSS. The statistical significance level was set at $\alpha<0.05$. Statistical analyses were conducted using SPSS Statistics version 20 (IBM, USA).

\section{Results}

Kinematics and kinetics in the young adults and the elderly during transitioning from flat ground to stair ascent

Joint profiles of biomechanics in the young vs. elderly males during transition from level walking-to-stair ascent are illustrated in Fig. 4.

In the early swing phase, the elderly showed greater dorsiflexion (AA_1) than that of the young, followed by greater hip joint flexion (HA_1). In the terminal swing phase, more extension of the ankle joint appeared in the elderly males.

Distinct differences in joint biomechanics of the two groups were observed during the stance phase (after $33 \%$ of the gait cycle). During the stance phase, the elderly showed greater flexion in the hip joint compared to the young adults. For the ankle joint, particularly, constantly decreasing dorsiflexion appeared in young adults; however, in the elderly, dorsiflexion was first sustained and then increased, followed by a rapid decrease. Compared with the young group, larger hip extensor moment and larger hip joint positive power, smaller knee extensor moment and smaller knee joint positive power, and larger peak plantar-flexor positive power appeared in the elderly. Similar results were also obtained for the support moment. Peak support moment was small in the first half of the stance phase, whereas a large support moment appeared in the second half of the stance phase.

\section{Changes in the joint profiles when VSS was applied}

When the VSS was applied, joint biomechanics were affected, as shown in Fig. 5. For the joint angle, knee flexion was decreased and dorsiflexion was increased in the swing phase, whereas both knee flexion and dorsiflexion were increased in the stance phase. For the joint moment, an increase in hip extensor moment at the early stance phase then an increase in the plantar-flexor moment and a reduction in knee flexor moment were observed. For the joint power, both hip extensor positive power and plantar-flexor negative power were increased. Support moment was increased in all stance phases.

\section{Changes dependent on the frequency of the VSS}

Significant changes depending on the frequency of the VSS are presented in Tables 1, 2, 3 and 4.

HA_1 without applying the VSS was $67.8 \pm 4.1 \mathrm{deg}$. When the VSS was applied, HA_1 at $180 \mathrm{~Hz}, 190 \mathrm{~Hz}$, and $250 \mathrm{~Hz}$ was $66.6 \pm 3.8 \mathrm{deg}$., $67.2 \pm 3.8 \mathrm{deg}$., and $67.4 \pm 3.3 \mathrm{deg}$., respectively, with no differences between frequencies (all $p>0.05$ ). Likewise, the second peak hip flexion angles (HA_2) for the NS condition, $180 \mathrm{~Hz}$, $190 \mathrm{~Hz}$, and $250 \mathrm{~Hz}$ were $4.9 \pm 5.1 \mathrm{deg}$., $7.3 \pm 3.5 \mathrm{deg}$., $5.9 \pm 4.8 \mathrm{deg}$., and $6.3 \pm 5.1 \mathrm{deg}$., respectively. There were no substantial differences between frequencies (all $p>0.05)$.

The first peak angle of the knee joint (KA_1) decreased when the VSS was applied except in the case of $250 \mathrm{~Hz}$. KA_1 during the NS was $94.6 \pm 4.3 \mathrm{deg}$., and in the case of $180 \mathrm{~Hz}$, and $190 \mathrm{~Hz}$ stimulation was $91.0 \pm 7.1 \mathrm{deg}$. (95\% CI: $0.89-6.34, p=0.015$ ), and $92.0 \pm 8.5 \mathrm{deg}$. (95\% CI: $0.88-5.34, p=0.044)$, respectively. The last flexion angle of the knee joint (KA_3) was $18.1 \pm 5.4 \mathrm{deg}$. without the VSS. KA_3 increased significantly, when the VSS was applied. KA_3 was $21.3 \pm 4.6 \mathrm{deg}$. at the $180 \mathrm{~Hz}(95 \%$ CI: $-5.33--1.06, p=0.008), 20.6 \pm 5.6 \mathrm{deg}$. at the $190 \mathrm{~Hz}$ (95\% CI: $-4.28--0.71, p=0.012$ ), and $20.4 \pm 5.7 \mathrm{deg}$. at the $250 \mathrm{~Hz}$ (95\% CI: $-4.19--0.32, p=0.027)$.

AA_1 was $15.3 \pm 3.4 \mathrm{deg}$. for the $180 \mathrm{~Hz}$ condition, $15.4 \pm 3.7 \mathrm{deg}$. for the $190 \mathrm{~Hz}$, and $15.2 \pm 3.6 \mathrm{deg}$. for the $250 \mathrm{~Hz}$, which was significantly greater than that of the NS condition $(12.6 \pm 3.5 \mathrm{deg}$., all $p<0.05)$. However, there was no significant difference between frequencies (all $p>0.05$ ). The last ankle dorsiflexion peak (AA_4) of the NS was $24.1 \pm 3.2 \mathrm{deg}$.. When the VSS was applied, AA_4 increased except at the $250 \mathrm{~Hz}$ stimulation. In the case of $180 \mathrm{~Hz}$, and $190 \mathrm{~Hz}, \mathrm{AA} \_4$ was $26.4 \pm 2.4(p=0.017)$, and $25.6 \pm 2.4 \quad(p=0.045)$, respectively. In particular, there was a significant difference between the $180 \mathrm{~Hz}$

\footnotetext{
(See figure on next page.)
}

Fig. 4 Profiles of lower-limb joints in both groups during transition from level walking to stair ascent. A Hip joint angle; B Knee joint angle; C Ankle joint angle; D Hip joint moment; E Knee joint moment; $\mathbf{F}$ Ankle joint moment; $\mathbf{G}$ Hip joint power; $\mathbf{H}$ Knee joint power; I Ankle joint power; J Support moment; For the joint angle, $(+)$ indicates joint flexion and (-) indicates joint extension; For the joint moment, $(+)$ indicates joint flexor moment and $(-)$ indicates joint extensor moment; For the support moment, $(+)$ indicates sum of extensor moments of the lower-limb joints; HA: Hip joint angle; KA: Knee joint angle; AA: Ankle joint angle; HM: Hip joint moment; KM: Knee joint Moment; AM: Ankle joint moment; HP: Hip joint power; KP: Knee joint power; AP: Ankle joint power; SM: Support moment 


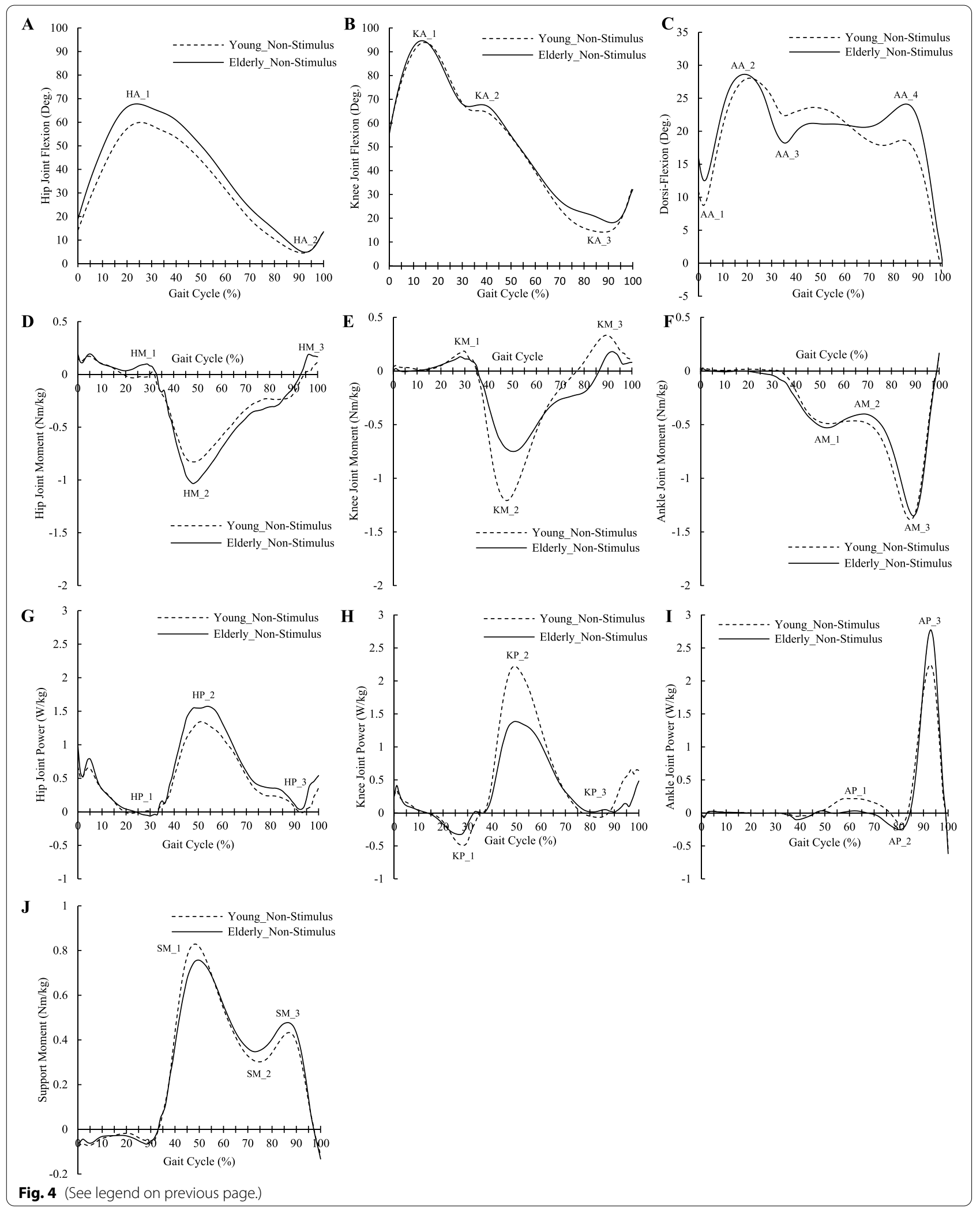


and the $250 \mathrm{~Hz}$ conditions $(180 \mathrm{~Hz}: 26.4 \pm 2.4$ vs. $250 \mathrm{~Hz}$ : $25.0 \pm 2.4, p=0.003)$.

Concerning the joint moment, the HFM_1 increased in all the VSS conditions. The HFM_1 without the VSS was $0.093 \pm 0.048 \mathrm{Nm} / \mathrm{kg}$. In the case of $180 \mathrm{~Hz}$, $190 \mathrm{~Hz}$, and $250 \mathrm{~Hz}$ stimulus, it was $0.114 \pm 0.045 \mathrm{Nm} /$ $\mathrm{kg}, 0.109 \pm 0.045 \mathrm{Nm} / \mathrm{kg}$, and $0.111 \pm 0.043 \mathrm{Nm} / \mathrm{kg}$ (all $p<0.001$ ), respectively. In addition, significant differences were observed between $180 \mathrm{~Hz}$ stimulus and both $190 \mathrm{~Hz}$ (Z-value: $-3.855, p<0.001$ ) and $250 \mathrm{~Hz}$ (Z-value: -2.676 , $p=0.007)$ stimuli.

Similarly, the HFM_2 increased when the VSS was applied. The HFM_2 during the NS condition was $0.134 \pm 0.069 \mathrm{Nm} / \mathrm{kg}$, and in the case of $180 \mathrm{~Hz}$, $190 \mathrm{~Hz}$, and $250 \mathrm{~Hz}$ stimulus was $0.167 \pm 0.064 \mathrm{Nm} / \mathrm{kg}$, $0.174 \pm 0.063 \mathrm{Nm} / \mathrm{kg}$, and $0.153 \pm 0.078$, respectively (all $p<0.05)$. Additionally, significant differences were found between $250 \mathrm{~Hz}$ stimulus and both $180 \mathrm{~Hz}$ (Z-value: $-2.201, p=0.016)$ and $190 \mathrm{~Hz}$ (Z-value: -2.201 , $p=0.004)$ stimuli.

The mean moment of the hip extensor (HEM) was $-0.513 \pm 0.299 \mathrm{Nm} / \mathrm{kg}$ in the case of NS. When the VSS was applied, HEM increased significantly in comparison to the NS. HEM was $-0.544 \pm 0.317 \mathrm{Nm} / \mathrm{kg}$ at $180 \mathrm{~Hz}$ (Z-value $-6.331, p<0.001),-0.560 \pm 0.322 \mathrm{Nm} /$ $\mathrm{kg}$ at $190 \mathrm{~Hz}$ (Z-value: $\quad-5.632, \quad p<0.001$ ), and $-0.549 \pm 0.318 \mathrm{Nm} / \mathrm{kg}$ at $250 \mathrm{~Hz}$ (Z-value: -5.897 , $p<0.001)$ stimulus. Significant differences between frequencies did not appear (all $p>0.05$ ).

KEM decreased significantly during VSS application compared to the NS except in the case of $250 \mathrm{~Hz}$. KEM without applying the VSS was $-0.406 \pm 0.218 \mathrm{Nm} / \mathrm{kg}$. $\mathrm{KEM}$ at $180 \mathrm{~Hz}$, and $190 \mathrm{~Hz}$ was $-0.384 \pm 0.243 \mathrm{Nm} /$ $\mathrm{kg}$ (Z-value: $-4.462, p<0.001)$, and $-0.397 \pm 0.230 \mathrm{Nm} /$ $\mathrm{kg}$ (Z-value: $-2.659, \quad p=0.008)$, respectively. There was a significant difference between all stimulus conditions. KEM changed from $-0.384 \pm 0.243 \mathrm{Nm} / \mathrm{kg}$ at $180 \mathrm{~Hz}$ to $-0.397 \pm 0.230 \mathrm{Nm} / \mathrm{kg}$ at $190 \mathrm{~Hz}$ (Z-value: $-4.544, p<0.001)$ and to $-0.404 \pm 0.225$ at $250 \mathrm{~Hz}$ (Z-value: $-4.991, p<0.001$ ). The change between $190 \mathrm{~Hz}$ and $250 \mathrm{~Hz}$ was significant as well (Z-value: -3.861 , $p<0.001$ ).

For KFM_2, when the VSS applied the value decreased significantly. KFM_2 in the case of NS was $0.111 \pm 0.048 \mathrm{Nm} / \mathrm{kg} ; 0.080 \pm 0.029$ at $180 \mathrm{~Hz}(95 \% \mathrm{CI}$ :
$0.02-0.05, p=0.001) ; 0.083 \pm 0.028$ at $190 \mathrm{~Hz}(95 \% \mathrm{CI}$ $0.02-0.05, p=0.02)$ and $0.055 \pm 0.023$ at $250 \mathrm{~Hz}(95 \% \mathrm{CI}$ : $0.04-0.08, p<0.001)$.

Similar to KEM, there were significant difference between all VSS conditions. Between $180 \mathrm{~Hz}$ and $190 \mathrm{~Hz}$ KFM $\_2$ changed from $0.080 \pm 0.029 \mathrm{Nm} / \mathrm{kg}$ to $0.083 \pm 0.028 \mathrm{Nm} / \mathrm{kg}$ (95\% CI: $-0.004--0.001, p=0.003)$; between $180 \mathrm{~Hz}$ and $250 \mathrm{~Hz}$ from $0.080 \pm 0.029 \mathrm{Nm} /$ $\mathrm{kg}$ to $0.055 \pm 0.023$ (95\% CI: $0.02-0.03, p<0.001$ ) and between $190 \mathrm{~Hz}$ and $250 \mathrm{~Hz}$ from $0.083 \pm 0.028 \mathrm{Nm} / \mathrm{kg}$ to $0.055 \pm 0.023$ (95\% CI: 0.02-0.03, $p<0.001$ ).

When the VSS applied, AEM increased significantly. Compared to the NS $(-0.465 \pm 0.361 \mathrm{Nm} / \mathrm{kg})$, AEM at $180 \mathrm{~Hz}, 190 \mathrm{~Hz}$, and $250 \mathrm{~Hz}$ was $-0.568 \pm 0.359 \mathrm{Nm} /$ $\mathrm{kg}$ (Z-value: $-4.598, \quad p<0.001), \quad-0.597 \pm 0.361 \mathrm{Nm} / \mathrm{kg}$ (Z-value: $-5.261, p<0.001)$, and $-0.553 \pm 0.351$ (Z-value: $-4.454, p<0.001)$, respectively. In addition, there was a significant difference between all frequencies. Between $180 \mathrm{~Hz}$ and $190 \mathrm{~Hz}$ AEM changed from $-0.568 \pm 0.359 \mathrm{Nm} / \mathrm{kg}$ to $-0.597 \pm 0.361 \mathrm{Nm} / \mathrm{kg}$ (Z-value: $-3.689, p=0.015$ ); between $180 \mathrm{~Hz}$ and $250 \mathrm{~Hz}$ from $-0.568 \pm 0.359 \mathrm{Nm} / \mathrm{kg}$ to $-0.553 \pm 0.351 \mathrm{Nm} / \mathrm{kg}$ (Z-value: $-3.486, p<0.001)$ and between $190 \mathrm{~Hz}$ and $250 \mathrm{~Hz}$ from $-0.597 \pm 0.361 \mathrm{Nm} / \mathrm{kg}$ to $-0.553 \pm 0.351 \mathrm{Nm} / \mathrm{kg}$ (Z-value: $-4.302, p<0.001$ ).

SM without the VSS was $0.446 \pm 0.189 \mathrm{Nm} / \mathrm{kg}$. When the VSS of $180 \mathrm{~Hz}, 190 \mathrm{~Hz}$, and $250 \mathrm{~Hz}$ was applied, SM increased to $0.481 \pm 0.195 \mathrm{Nm} / \mathrm{kg}$ (Z-value: -5.785 , $p<0.001$ ), $0.484 \pm 0.202$ (Z-value: $-5.847, p<0.001$ ), and $0.473 \pm 0.195$ (Z-value: $-5.354, p<0.001$ ), respectively. In addition, there was a significant difference between all frequencies $(180 \mathrm{~Hz}$ vs. $190 \mathrm{~Hz}, \mathrm{Z}$-value: -2.643 , $p=0.008 ; 180 \mathrm{~Hz}$ vs. $250 \mathrm{~Hz}, \mathrm{Z}$-value: $-4.916, p<0.001$; $190 \mathrm{~Hz}$ vs. $250 \mathrm{~Hz}$, Z-value: $-5.696, p<0.001)$.

HPP_1 increased when applying the VSS of $190 \mathrm{~Hz}$ and $250 \mathrm{~Hz}$. HPP_1 for the NS was $0.787 \pm 0.532 \mathrm{~W} / \mathrm{kg}$. HPP_1 at the $190 \mathrm{~Hz}$ and $250 \mathrm{~Hz}$ was $0.851 \pm 0.595 \mathrm{~W} /$ $\mathrm{kg}$ (Z-value: $-5.782, p<0.001)$ and $0.837 \pm 0.604 \mathrm{~W} /$ $\mathrm{kg}$ (Z-value: $-4.846, p<0.001$ ), respectively, which was statistically different from the $180 \mathrm{~Hz}$ stimulus. In case of the $180 \mathrm{~Hz}$ vs. $190 \mathrm{~Hz}, \mathrm{HPP} \_1$ was $0.786 \pm 0.584$ vs. $0.851 \pm 0.595$ (Z-value: $-4.710, p<0.001$ ) and in case of the $180 \mathrm{~Hz}$ vs. $250 \mathrm{~Hz}$ was $0.786 \pm 0.584 \mathrm{~W} / \mathrm{kg}$ vs. $0.837 \pm 0.604 \mathrm{~W} / \mathrm{kg}(\mathrm{Z}$-value: $-6.463, p<0.001)$.

KNP had a statistically significant tendency to decrease. $\mathrm{KNP}$ was $-0.170 \pm 0.119 \mathrm{~W} / \mathrm{kg}$ in the case of NS, while

(See figure on next page.)

Fig. 5 Profiles of the elderly during transition from level walking to stair ascent upon VSS application. A Hip joint angle; B Knee joint angle; C Ankle joint angle; $\mathbf{D}$ Hip joint moment; E Knee joint moment; $\mathbf{F}$ Ankle joint moment; $\mathbf{G}$ Hip joint power; $\mathbf{H}$ Knee joint power; I Ankle joint power; J Support moment; For the joint angle, $(+)$ indicates joint flexion and $(-)$ indicates joint extension; For the joint moment, $(+)$ indicates joint flexor moment and (-) indicates joint extensor moment; For the support moment, (+) indicates sum of extensor moments of the lower-limb joints; Arrows represent change by the VSS; HFM: Hip flexor moment; HEM: Hip extensor moment; KFM: Knee flexor moment; KEM: Knee extensor moment; AEM: Ankle extensor moment; HPP: Hip positive power; KNP: Knee negative power; KPP: Knee positive power; ANP: Ankle negative power; APP: Ankle positive power; SM:Support moment 


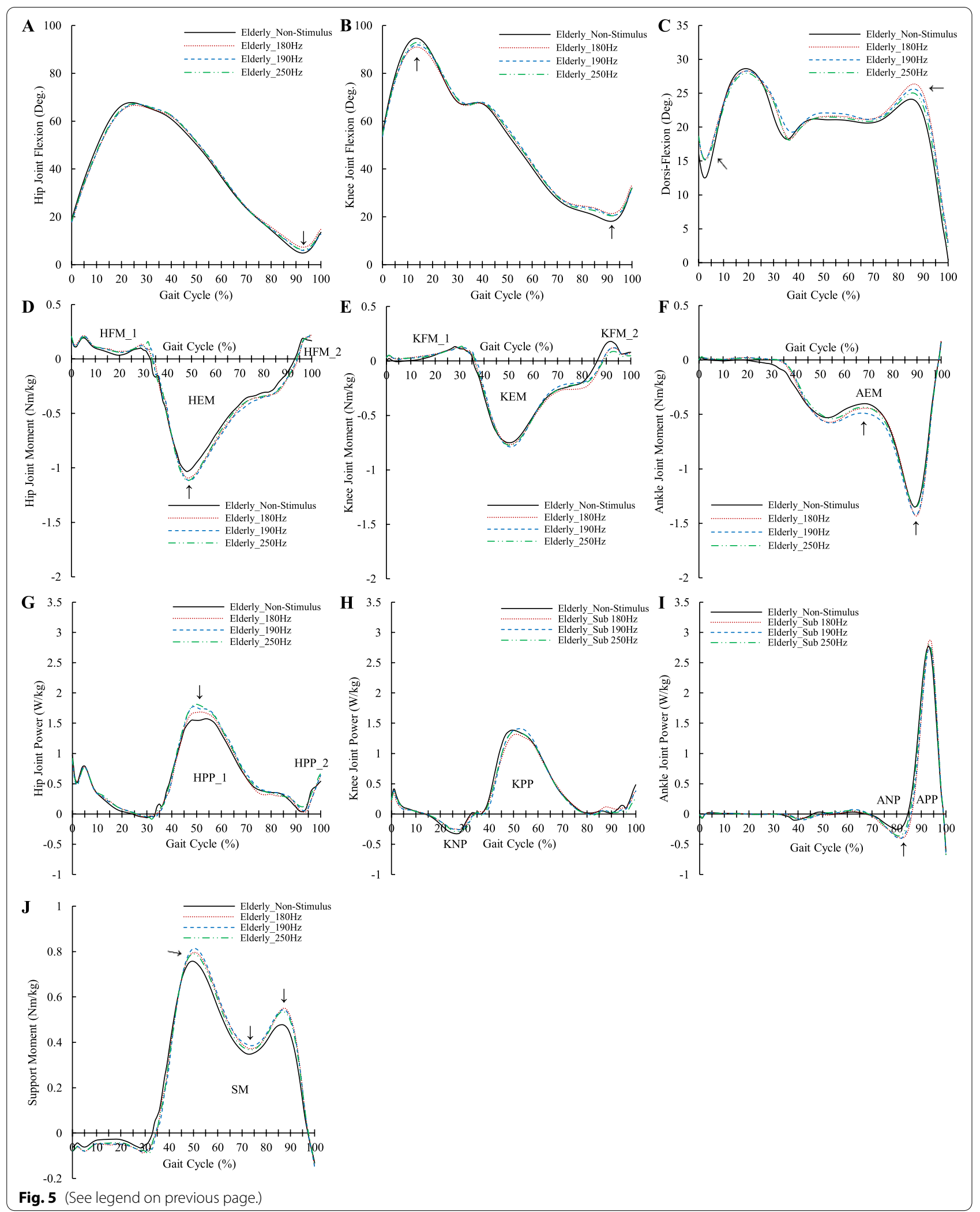


Table 1 Peak joint angle parameters depending on the frequency of the VSS in the elderly

\begin{tabular}{|c|c|c|c|c|c|}
\hline & & $\begin{array}{l}\text { Elderly } \\
\text { Non-Stimulus }\end{array}$ & $\begin{array}{l}\text { Elderly } \\
180 \mathrm{~Hz} \text { Stimulus }\end{array}$ & $\begin{array}{l}\text { Elderly } \\
190 \mathrm{~Hz} \text { Stimulus }\end{array}$ & $\begin{array}{l}\text { Elderly } \\
250 \mathrm{~Hz} \text { Stimulus }\end{array}$ \\
\hline \multirow[t]{8}{*}{ HipJointAngle } & HA_1 & $67.8 \pm 4.1$ & $66.6 \pm 3.8$ & $67.2 \pm 3.8$ & $67.4 \pm 3.3$ \\
\hline & $95 \% \mathrm{Cl}$ & & {$[-0.26,2.64]$} & {$[-0.82,2.07]$} & {$[-0.88,1.74]$} \\
\hline & t-value* & & 1.85 & 0.98 & 0.74 \\
\hline & $p$ value* & & 0.098 & 0.353 & 0.480 \\
\hline & HA_2 & $4.9 \pm 5.1$ & $7.3 \pm 3.5$ & $5.9 \pm 4.8$ & $6.3 \pm 5.1$ \\
\hline & $95 \% \mathrm{Cl}$ & & {$[-5.81,1.05]$} & {$[-2.41,0.39]$} & {$[-3.28,0.39]$} \\
\hline & t-value* & & -1.57 & -1.63 & -1.79 \\
\hline & $p$ value* & & 0.151 & 0.137 & 0.108 \\
\hline \multirow[t]{9}{*}{ KneeJointAngle } & KA_1 & $94.6 \pm 4.3$ & $* 91.0 \pm 7.1$ & ${ }^{*} 92.0 \pm 8.5$ & $92.9 \pm 8.5$ \\
\hline & $95 \% \mathrm{Cl}$ & & {$[0.89,6.34]$} & {$[0.88,5.34]$} & {$[-1.21,4.70]$} \\
\hline & t-value* & & 3.022 & 2.34 & 1.34 \\
\hline & $p$ value* & & 0.015 & 0.044 & 0.214 \\
\hline & KA_2 & $68.1 \pm 2.9$ & $68.3 \pm 2.2$ & $69.6 \pm 3.3$ & $69.3 \pm 3.6$ \\
\hline & KA_3 & $18.1 \pm 5.4$ & $* 21.3 \pm 4.6$ & *20.6 \pm 5.6 & $* 20.4 \pm 5.7$ \\
\hline & $95 \% \mathrm{Cl}$ & & {$[-5.33,-1.06]$} & {$[-4.28,-0.71]$} & {$[-4.19,-0.32]$} \\
\hline & t-value* & & -3.39 & -3.16 & -2.64 \\
\hline & $p$ value* & & 0.008 & 0.012 & 0.027 \\
\hline \multirow[t]{16}{*}{ AnkleJointAngle } & AA_1 & $12.6 \pm 3.5$ & $* 15.3 \pm 3.4$ & $* 15.4 \pm 3.7$ & $* 15.2 \pm 3.6$ \\
\hline & $95 \% \mathrm{Cl}$ & & {$[-4.62,-0.75]$} & {$[-5.51,-0.02]$} & {$[-5.11,-0.03]$} \\
\hline & t-value* & & -3.14 & -2.28 & -2.29 \\
\hline & $p$ value* & & 0.012 & 0.049 & 0.048 \\
\hline & AA_2 & $28.6 \pm 2.8$ & $28.3 \pm 3.2$ & $28.3 \pm 3.1$ & $28.0 \pm 2.8$ \\
\hline & AA_3 & $18.2 \pm 4.0$ & $18.3 \pm 5.1$ & $19.3 \pm 4.7^{c}$ & $18.1 \pm 5.3^{b}$ \\
\hline & $95 \% \mathrm{Cl}^{\mathrm{a}, \mathrm{b}, \mathrm{c}}$ & & - & {$[0.03,2.30]$} & {$[0.03,2.30]$} \\
\hline & $t$-value $e^{a, b, c}$ & & - & 2.32 & 2.32 \\
\hline & $p$ value $e^{a, b, c}$ & & - & $0.045^{c}$ & $0.045^{b}$ \\
\hline & AA_4 & $24.1 \pm 3.2$ & $* 26.4 \pm 2.4$ & $* 25.6 \pm 2.4$ & $25.0 \pm 2.4^{\mathrm{a}}$ \\
\hline & $95 \% \mathrm{Cl}^{*}$ & & {$[-3.97,-0.50]$} & {$[2.95,-0.04]$} & {$[-2.82,0.97]$} \\
\hline & t-value* & & -2.91 & -2.33 & -1.10 \\
\hline & $p$ value ${ }^{*}$ & & 0.017 & 0.045 & 0.298 \\
\hline & $95 \% \mathrm{Cl}^{\mathrm{a}, \mathrm{b}, \mathrm{c}}$ & & {$[0.58,2.03]$} & - & {$[0.58,2.03]$} \\
\hline & $t$-value $e^{a, b, c}$ & & 4.07 & - & 4.07 \\
\hline & $p$ value $e^{a, b, c}$ & & $0.003^{c}$ & - & $0.003^{\mathrm{a}}$ \\
\hline
\end{tabular}

Mean \pm Standard deviation, Unit: Degree, $C /$ Confidence interval, $t$-value paired t-test

* indicates significant difference between Non-Stimulus and Stimulus $(p<0.05)$

${ }^{a}$ indicates significant difference from $180 \mathrm{~Hz}$ stimulus $(p<0.05)$

b indicates significant difference from $190 \mathrm{~Hz}$ stimulus $(p<0.05)$

c indicates significant difference from $250 \mathrm{~Hz}$ stimulus $(p<0.05)$

at $180 \mathrm{~Hz}$ it was $-0.141 \pm 0.091 \mathrm{~W} / \mathrm{kg}$ (Z-value: -2.688 , $p=0.007$ ) and $-0.141 \pm 0.092 \mathrm{~W} / \mathrm{kg}$ at $190 \mathrm{~Hz}$ (Z-value: $-2.427, p=0.015)$. There was no significant difference between the $250 \mathrm{~Hz}$ stimulus and the NS conditions, whereas the $250 \mathrm{~Hz}$ condition showed a significant difference from both the $180 \mathrm{~Hz}$ and $190 \mathrm{~Hz}$. In the case of $250 \mathrm{~Hz}$ vs. $180 \mathrm{~Hz}$ the value was $-0.154 \pm 0.102 \mathrm{~W} /$ $\mathrm{kg}$ vs. $-0.141 \pm 0.091 \mathrm{~W} / \mathrm{kg}$ (Z-value: $-3.584, p<0.001$ ), and in the case of $250 \mathrm{~Hz}$ vs. $190 \mathrm{~Hz}$ the value was
$-0.154 \pm 0.102 \mathrm{~W} / \mathrm{kg}$ vs. $-0.141 \pm 0.092 \mathrm{~W} / \mathrm{kg}$ (Z-value: $-2.28, p=0.006$ ).

ANP increased in all of stimulus conditions. ANP during the NS was $-0.135 \pm 0.090 \mathrm{~W} / \mathrm{kg}$, and in the case of $180 \mathrm{~Hz}, 190 \mathrm{~Hz}$, and $250 \mathrm{~Hz}$ stimulation was $-0.214 \pm 0.138$ (95\% CI: $0.05-0.13, p<0.001$ ), $-0.222 \pm 0.1137 \quad(95 \% \quad \mathrm{CI}: \quad 0.06-0.11, \quad p<0.001)$, and $-0.197 \pm 0.126 \quad(95 \%$ CI: $0.04-0.08, \quad p<0.001)$, respectively. In addition, there was a significant 
Table 2 Joint moments depending on the frequency of the VSS in the elderly

\begin{tabular}{|c|c|c|c|c|c|}
\hline & & $\begin{array}{l}\text { Elderly } \\
\text { Non-Stimulus }\end{array}$ & $\begin{array}{l}\text { Elderly } \\
180 \mathrm{~Hz} \text { Stimulus }\end{array}$ & $\begin{array}{l}\text { Elderly } \\
190 \mathrm{~Hz} \text { Stimulus }\end{array}$ & $\begin{array}{l}\text { Elderly } \\
250 \mathrm{~Hz} \text { Stimulus }\end{array}$ \\
\hline \multirow[t]{13}{*}{ HipJointMoment } & HFM_1 & $0.093 \pm 0.048$ & ${ }^{*} 0.114 \pm 0.045^{b c}$ & ${ }^{*} 0.109 \pm 0.045^{\mathrm{a}}$ & ${ }^{*} 0.111 \pm 0.043^{\mathrm{a}}$ \\
\hline & Z-value* & & -5.012 & -5.012 & -5.012 \\
\hline & $p$ value ${ }^{*}$ & & $p<0.001$ & $p<0.001$ & $p<0.001$ \\
\hline & Z-value ${ }^{a, b, c}$ & & - & -3.855 & -2.676 \\
\hline & $p$ value $e^{a, b, c}$ & & - & $p<0.001^{\mathrm{a}}$ & $0.007^{\mathrm{a}}$ \\
\hline & HEM & $-0.513 \pm 0.299$ & ${ }^{*}-0.544 \pm 0.317$ & $*-0.560 \pm 0.322$ & ${ }^{*}-0.549 \pm 0.318$ \\
\hline & Z-value* & & -6.331 & -5.632 & -5.897 \\
\hline & $p$ value* & & $p<0.001$ & $p<0.001$ & $p<0.001$ \\
\hline & HFM_2 & $0.134 \pm 0.069$ & ${ }^{*} 0.167 \pm 0.064$ & ${ }^{*} 0.174 \pm 0.063$ & ${ }^{*} 0.153 \pm 0.078^{\mathrm{ab}}$ \\
\hline & Z-value* & & -2.201 & -2.201 & -2.197 \\
\hline & $p$ value* & & 0.028 & 0.028 & 0.028 \\
\hline & Z-value ${ }^{a, b, c}$ & & -2.201 & -2.201 & - \\
\hline & $p$ value $e^{a, b, c}$ & & $0.016^{c}$ & $0.004^{c}$ & - \\
\hline \multirow[t]{15}{*}{ KneeJointMoment } & KFM_1 & $0.061 \pm 0.043$ & $0.060 \pm 0.035$ & $0.061 \pm 0.035^{c}$ & $0.058 \pm 0.035^{b}$ \\
\hline & Z-value ${ }^{a, b, c}$ & & - & -2.150 & -2.150 \\
\hline & $p$ value $a, b, c$ & & - & $0.032^{c}$ & $0.032^{b}$ \\
\hline & KEM & $-0.406 \pm 0.218$ & $*-0.384 \pm 0.243^{b c}$ & ${ }^{*}-0.397 \pm 0.230^{\mathrm{ac}}$ & $-0.404 \pm 0.225^{\mathrm{ab}}$ \\
\hline & Z-value* & & -4.462 & -2.659 & -1.575 \\
\hline & $p$ value ${ }^{*}$ & & $p<0.001$ & 0.008 & 0.115 \\
\hline & Z-value ${ }^{a, b, c}$ & & -4.544 & -3.861 & -4.991 \\
\hline & $p$ value $\mathrm{e}^{\mathrm{a}, \mathrm{b}, \mathrm{c}}$ & & $p<0.001^{b}$ & $p<0.001^{c}$ & $p<0.001^{\mathrm{a}}$ \\
\hline & KFM_2 & $0.111 \pm 0.048$ & ${ }^{*} 0.080 \pm 0.029^{b c}$ & ${ }^{*} 0.083 \pm 0.028^{\mathrm{ac}}$ & ${ }^{*} 0.055 \pm 0.023^{a b}$ \\
\hline & $95 \% \mathrm{Cl}$ & & {$[0.02,0.05]$} & {$[0.02,0.05]$} & {$[0.04,0.08]$} \\
\hline & t-value* & & 4.49 & 4.15 & 6.49 \\
\hline & $p$ value* & & 0.001 & 0.002 & $p<0.001$ \\
\hline & $95 \%$ Cla,b,c & & {$[-0.004,-0.001]$} & {$[0.02,0.03]$} & {$[0.02,0.03]$} \\
\hline & t-valuea,b,c & & -3.81 & 11.92 & 10.49 \\
\hline & $p$ value $e^{a, b, c}$ & & $0.003^{b}$ & $p<0.001^{c}$ & $p<0.001^{\mathrm{a}}$ \\
\hline \multirow[t]{5}{*}{ AnkleJointMoment } & AEM & $-0.465 \pm 0.361$ & ${ }^{*}-0.568 \pm 0.359^{b c}$ & ${ }^{*}-0.597 \pm 0.361^{\mathrm{ac}}$ & ${ }^{*}-0.553 \pm 0.351^{\mathrm{ab}}$ \\
\hline & Z-value* & & -4.598 & -5.261 & -4.454 \\
\hline & $p$ value ${ }^{*}$ & & $p<0.001$ & $p<0.001$ & $p<0.001$ \\
\hline & Z-value ${ }^{a, b, c}$ & & -3.689 & -4.302 & -3.486 \\
\hline & $p$ value $e^{a, b, c}$ & & $0.015^{b}$ & $p<0.001^{c}$ & $p<0.001^{a}$ \\
\hline
\end{tabular}

Mean \pm Standard deviation, Unit: N.m/kg (Newton meters/kilogram), +: Flexor moment, -: Extensor moment

$\mathrm{Cl}$ Confidence interval, $t$-value paired t-test, $Z$-valueWilcoxon signed rank test

* indicates significant difference between Non-Stimulus and Stimulus $(p<0.05)$

a indicates significant difference from $180 \mathrm{~Hz}$ stimulus $(p<0.05)$

b indicates significant difference from $190 \mathrm{~Hz}$ stimulus $(p<0.05)$

c indicates significant difference from $250 \mathrm{~Hz}$ stimulus $(p<0.05)$

difference between $190 \mathrm{~Hz}$ and $250 \mathrm{~Hz}$ (95\% CI: -0.04 $-0.01, p=0.004$ ) stimuli.

\section{Discussion}

The present pilot study has examined the transition from level walking-to-stair ascent of the elderly by comparing with young adults and investigated the effect of the VSS on the transition movement in the elderly and the changes that occur depending on the frequency of the VSS.

Participants in the present study are the same as in our previous study [27]. Our previous study [27] examined the influence of local tendon vibration on postural sway during sit-to-stand movement, whereas the present 
Table 3 Support moment parameters depending on the frequency of the VSS in the elderly

\begin{tabular}{|c|c|c|c|c|c|}
\hline & & $\begin{array}{l}\text { Elderly } \\
\text { Non-Stimulus }\end{array}$ & $\begin{array}{l}\text { Elderly } \\
180 \mathrm{~Hz} \text { Stimulus }\end{array}$ & $\begin{array}{l}\text { Elderly } \\
190 \mathrm{~Hz} \text { Stimulus }\end{array}$ & $\begin{array}{l}\text { Elderly } \\
250 \mathrm{~Hz} \text { Stimulus }\end{array}$ \\
\hline \multirow[t]{5}{*}{ SupportMoment } & SM & $0.446 \pm 0.189$ & ${ }^{*} 0.481 \pm 0.195^{b c}$ & ${ }^{*} 0.484 \pm 0.202^{\mathrm{ac}}$ & ${ }^{*} 0.473 \pm 0.195^{\mathrm{ab}}$ \\
\hline & Z-value* & & -5.785 & -5.847 & -5.354 \\
\hline & $p$ value* & & $p<0.001$ & $p<0.001$ & $p<0.001$ \\
\hline & Z-value ${ }^{a, b, c}$ & & -2.643 & -4.916 & -5.696 \\
\hline & $p$ value $e^{a, b, c}$ & & $0.008^{\mathrm{b}}$ & $p<0.001^{c}$ & $p<0.001^{\mathrm{a}}$ \\
\hline
\end{tabular}

Mean \pm Standard deviation, Unit: N.m/kg (Newton meters/kilogram)

Z-value Wilcoxon signed rank test

* indicates significant difference between Non-Stimulus and Stimulus $(p<0.05)$

a indicates significant difference from $180 \mathrm{~Hz}$ stimulus $(p<0.05)$

${ }^{\mathrm{b}}$ indicates significant difference from $190 \mathrm{~Hz}$ stimulus $(p<0.05)$

c indicates significant difference from $250 \mathrm{~Hz}$ stimulus $(p<0.05)$

study investigated the effect of the vibrotactile somatosensory stimulus on neuromotor control of the transition movement from level walking-to-stair ascent. That is, the topic, measure and analysis methods, the analyzed parameters and the motion in each study are different.

During the transition movements, in the first half of the stance, the elderly presented a higher function of the hip extensor to pull up compared to young adults. In the second half of the stance, dorsiflexion and plantar-flexor moment and power to the push-up was higher in the elderly than the young adults. When the VSS was applied, those results were further developed. The hip extensor function for the pull-up and the plantar-flexor function for the push-up increased. Consequentially, the extensor function of the lower extremity (i.e., support moment) increased during the entire stance phase. In addition, joint moment and power during the single-limb support phase were affected by the change in frequency of the VSS.

\section{Features of the transition from level walking to stair ascent in the elderly}

In the early swing phase, compared with young adults, the elderly showed higher dorsiflexion (AA_1), followed by higher hip flexion (HA_1) and dorsiflexion (AA_2). This could be the modality to pass a step of the staircase safely. In other words, it may be a strategy to ensure toeclearance to prevent tripping over the staircase.

After that, lower dorsiflexion (AA_3) appeared in the elderly compared to young adults. It is possibly being used to clearly land the foot on the staircase through more ankle extension than the young adults. Consequently, ankle extension induces smooth foot landing, resulting in a decreasing impact force from the step during the weight acceptance.
In the stance phase, both groups used dominantly the extensor of the hip and knee joint to the lift body. However, the modality of use was opposite between the two groups. The elderly predominantly used hip extensor, whereas the young adults used the knee extensor. This can be attributed to weakness of the quadriceps femoris. It is a well-known fact that the elderly have lower muscle strength in the lower extremity compared with young adults. In particular, Hortobágyi et al. [37] reported that older adults had 60\% lower maximal leg press moments compared with young adults. Due to this, the support moment could appear low in the elderly (SM_1). This could induce more activity of the hip extensor to compensate for the weakened knee extensor, and in the case of the plantar-flexor, it contributes to some compensation. These features could provide a clinical reference for training the quadricep muscles in the elderly.

Although joints of the hip and knee extended continuously in both groups, dorsiflexion decreased by plantarflexor activity (AP_1) in young adults, whereas it was sustained in the elderly. This may be a strategy of the elderly to ensure stability while ascending the stairs. First, sway of the shank can be minimized by fixing the ankle joint. Second, if the ankle joint is extended, the position of the center of mass (COM) increases, which may cause postural instability due to COM acceleration. Finally, knee extension that is created by pulling the shank back, which contributes to the forward acceleration of the $\mathrm{COM}$, can be prevented by restricting activity of the plantar-flexor.

In the late stance phase, dorsiflexion and knee flexion were higher in the elderly than in the young adults. This can contribute to a reduction in COM height, foot landing of the contralateral leg, and weight shift to the 
Table 4 Joint power parameters depending on the frequency of the VSS in the elderly

\begin{tabular}{|c|c|c|c|c|c|}
\hline & & $\begin{array}{l}\text { Elderly } \\
\text { Non-Stimulus }\end{array}$ & $\begin{array}{l}\text { Elderly } \\
180 \mathrm{~Hz} \text { Stimulus }\end{array}$ & $\begin{array}{l}\text { Elderly } \\
190 \mathrm{~Hz} \text { Stimulus }\end{array}$ & $\begin{array}{l}\text { Elderly } \\
250 \mathrm{~Hz} \text { Stimulus }\end{array}$ \\
\hline \multirow[t]{12}{*}{ HipJointPower } & HPP_1 & $0.787 \pm 0.532$ & $0.786 \pm 0.584^{b c}$ & ${ }^{*} 0.851 \pm 0.595^{\mathrm{a}}$ & ${ }^{*} 0.837 \pm 0.604^{\mathrm{a}}$ \\
\hline & Z-value* & & -1.525 & -5.782 & -4.846 \\
\hline & $p$ value* & & 0.127 & $p<0.001$ & $p<0.001$ \\
\hline & Z-value $e^{a, b, c}$ & & -4.710 & -0.868 & -6.463 \\
\hline & $p$ value $\mathrm{a}^{\mathrm{a}, \mathrm{b}, \mathrm{c}}$ & & $p<0.001^{b}$ & $0.385^{c}$ & $p<0.001^{\mathrm{a}}$ \\
\hline & HPP_2 & $0.326 \pm 0.193$ & $0.323 \pm 0.225^{c}$ & $0.328 \pm 0.219^{c}$ & ${ }^{*} 0.395 \pm 0.195^{\mathrm{ab}}$ \\
\hline & $95 \% \mathrm{Cl}^{*}$ & & {$[-0.08,0.03]$} & {$[-0.09,0.02]$} & {$[-0.15,-0.05]$} \\
\hline & t-value* & & -1.23 & -1.36 & -4.91 \\
\hline & $p$ value* & & 0.264 & 0.222 & 0.003 \\
\hline & $95 \% \mathrm{Cl}^{\mathrm{a}, \mathrm{b}, \mathrm{c}}$ & & {$[-0.02,0.01]$} & {$[-0.09,-0.04]$} & {$[-0.11,-0.04]$} \\
\hline & $t$-value $e^{a, b, c}$ & & -0.75 & -6.36 & -4.93 \\
\hline & $p$ value $\mathrm{a}^{\mathrm{a}, \mathrm{b}, \mathrm{c}}$ & & $0.480^{b}$ & $0.001^{c}$ & $0.003^{\mathrm{a}}$ \\
\hline \multirow[t]{8}{*}{ KneeJointPower } & KNP & $-0.170 \pm 0.119$ & ${ }^{*}-0.141 \pm 0.091^{c}$ & ${ }^{*}-0.141 \pm 0.092^{c}$ & $-0.154 \pm 0.102^{\mathrm{ab}}$ \\
\hline & Z-value* & & -2.688 & -2.427 & -1.344 \\
\hline & $p$ value ${ }^{*}$ & & 0.007 & 0.015 & 0.179 \\
\hline & Z-value $e^{a, b, c}$ & & -1.792 & -2.728 & -3.584 \\
\hline & $p$ value $e^{a, b, c}$ & & $0.073^{b}$ & $0.006^{c}$ & $p<0.001^{\mathrm{a}}$ \\
\hline & KPP & $0.689 \pm 0.508$ & $0.609 \pm 0.483$ & ${ }^{*} 0.692 \pm 0.517$ & ${ }^{*} 0.705 \pm 0.489$ \\
\hline & Z-value* & & -0.198 & -3.876 & -3.832 \\
\hline & $p$ value* & & 0.843 & $p<0.001$ & $p<0.001$ \\
\hline \multirow[t]{11}{*}{ AnkleJointPower } & ANP & $-0.135 \pm 0.090$ & ${ }^{*}-0.214 \pm 0.138$ & ${ }^{*}-0.222 \pm 0.137^{c}$ & ${ }^{*}-0.197 \pm 0.126^{b}$ \\
\hline & $95 \% \mathrm{Cl}^{*}$ & & {$[0.05,0.13]$} & {$[0.06,0.11]$} & {$[0.04,0.08]$} \\
\hline & t-value* & & 4.90 & 7.42 & 6.15 \\
\hline & $p$ value $e^{*}$ & & $p<0.001$ & $p<0.001$ & $p<0.001$ \\
\hline & $95 \% \mathrm{Cl}^{\mathrm{a}, \mathrm{b}, \mathrm{c}}$ & & - & {$[-0.04,-0.01]$} & {$[-0.04,-0.01]$} \\
\hline & t-value $e^{a, b, c}$ & & - & -3.35 & -3.35 \\
\hline & $p$ value $\mathrm{a}^{\mathrm{a}, \mathrm{b}, \mathrm{c}}$ & & - & $0.004^{c}$ & $0.004^{b}$ \\
\hline & APP & $1.510 \pm 0.952$ & $1.519 \pm 1.021$ & $1.410 \pm 1.005^{c}$ & $1.598 \pm 0.934^{b}$ \\
\hline & $95 \% \mathrm{Cl}^{\mathrm{a}, \mathrm{b}, \mathrm{c}}$ & & - & {$[-0.14,-0.02]$} & {$[-0.14,-0.02]$} \\
\hline & t-value $e^{a, b, c}$ & & - & -2.70 & -2.70 \\
\hline & $p$ value $\mathrm{a}^{\mathrm{a}, \mathrm{b}, \mathrm{c}}$ & & - & $0.019^{c}$ & $0.019^{b}$ \\
\hline
\end{tabular}

Mean \pm Standard deviation, Unit:W/kg (Watt/kilogram), Cl Confidence interval $t$-value paired t-test, $Z$-value Wilcoxon signed rank test

* indicates significant difference between Non-Stimulus and Stimulus $(p<0.05)$

a indicates significant difference from $180 \mathrm{~Hz}$ stimulus $(p<0.05)$

b indicates significant difference from $190 \mathrm{~Hz}$ stimulus $(p<0.05)$

c indicates significant difference from $250 \mathrm{~Hz}$ stimulus $(p<0.05)$

opposite leg. For this, the support moment (SM_3) increased more, which was attributed to the extensor moments of the hip and knee joints. This is a modality for securing energy for the subsequent push-up and compensating for the weakened quadriceps femoris in the opposite leg.

At the end of the stance phase, the plantar-flexor positive power is greater in the elderly. This was attributed to the larger dorsiflexion just earlier, and was a strategy to counter the more flexed dorsiflexion and assist the pullup function of the proximal extensor of the opposite leg.

In summary, the elderly tended to use more hip extensors than young adults to lift the body, and to presumably ensure stability during locomotion, the extension of the ankle joint was restricted. In addition, the plantar-flexor power increased by increasing the flexion of the distal segments, possibly to assist the pull-up function of the opposite leg. 


\section{Effect of VSS on the transition from level walking to stair ascent in the elderly}

In the swing phase, after toe-off, dorsiflexion (i.e., AA_1) increased, followed by a decrease in knee joint flexion. Toe clearance was ensured more by the increased dorsiflexion, and the decreased knee joint flexion could have contributed to control foot-landing by compensating for increased dorsiflexion. Consequently, the VSS induced further toe clearance, resulting in more stable stepping and more cautious foot contact.

In the stance phase, the moments and positive powers of the hip extensor increased. This could indicate that the function of the hip extensor to lift-up the body was enhanced by the VSS and that features of the elderly in the pull-up phase were also developed. In addition, the support moments increased. Hence, the results indicated that VSS increased function of the body support during the single-limb support phase and contributed to the pull-up of the body by activating the hip extensor. Furthermore, moments of the plantar-flexor increased slightly during the first half of the stance phase, which may have contributed to an increase in the support moments. Consequently, VSS contributed to an increase in the body support function while transitioning from the double limb support stance phase to the single-limb support stance.

In the second half of the stance phase, an increase in the knee joint flexion, dorsiflexion, and support moments appeared; that is, the VSS possibly further reinforced the body support (i.e., an increase in the SMs and negative plantar-flexor powers) and contributed to increasing the push-up of the plantar-flexor and assisting the pull-up of the contralateral limb.

These results indicated that the VSS could further develop characteristics of the transition movement in the elderly. In summary as follows:

The VSS possibly ensures safer toe clearance by increasing dorsiflexion, enhancing lift-up function of the hip extensor, increasing body support during the single-limb support phase, and assisting in the push-up of the plantar-flexor and the pull-up of the contralateral limb.

Despite the listed effects of VSS, the duration of the transition can be lengthened due to the increase in joint flexion and support moment. With increasing joint flexion, more extensor activity and antagonist muscle activation are required to prevent lower-limb collapse, and to restrict joint movement, respectively. These are factors that increase the joint stiffness. Thus, future studies should include spatiotemporal variables and electromyography (EMG).

\section{Parameters depending on the frequencies of the VSS}

For the hip joint angle, although there were no significant differences under non-stimulus and stimulus conditions, HA_2 had a tendency to increase. For the knee joint angle, there was a significant difference between non-stimulus and stimulus in KA_1 and KA_3, despite no difference between frequencies. For the ankle joint angle, there was a statistically significant difference between non-stimulus and stimulus in the AA_1 and AA_4. In particular, statistical significance was found between $180 \mathrm{~Hz}$ and $250 \mathrm{~Hz}$ for AA_4.

Overall, the VSS can be considered to cause a change in kinematics, and the trend seems to be common at all frequencies. This common trend may have resulted from the fixed dimensions of the staircase. However, differences depending on frequencies may occur in kinetic parameters considering that the joint angles of each stimulus condition were different.

As shown in Table 2, statistically significant differences between the non-stimulus and stimuli appeared between each frequency pair. Furthermore, significant frequency-dependent differences were found in the support moment, a sum of extensor moments of the lower limb joints $[36,38]$, as shown in Table 4. Steyvers et al. [39] measured motor evoked potential (MEP) depending on vibration frequency and revealed that frequency-dependent effect appeared in the MEPs. Therefore, it is indicated that the VSS affects joint kinetics while transitioning from level walking to stair ascent, and thus it can be presumed that joint kinetics can be regulated depending on the VSS frequency; that is, the VSS could influence neuromotor control (NMC). As a result, performance degree in sub-biomechanical tasks (i.e., weight acceptance, pull-up, body support, and push-up) during transitioning from flat ground walking to stair climbing will be affected.

There were significant differences between each frequency pair in the KNP for foot landing, the HPP_1 for the pull-up, the SM for preventing lower-limb collapse, and the ANP for ensuring stability, supporting the lower-limb and assisting the opposite leg. Although not all frequencies, this indicated that the same function is performed during the transition, but the degree varies with the vibration frequency; that is, it suggests that the $\mathrm{NMC}$ of the transition is frequency dependent.

In conclusion, the VSS has the possibility to control the degree of performance of sub-biomechanical tasks by affecting the NMC. It can further develop the characteristics of the transition movement in the elderly. For more insight, future investigations on EMG and muscle synergy are required. 


\section{Role of VSS in assisting level walking-to-stair ascent and its application}

In this study, it was found that the elders' characteristics of the transition motion differed from those of young adults. The predominant characteristics were larger hip joint flexion (HA_1), sustained dorsiflexion and larger dorsiflexion (AA_4), higher moment (HM_2) and power (HP_2) of the hip extensor, higher power of the plantarflexor (AP_3) and the lower support moment (SM_1). These characteristics of the elderly might be an adaptation of motor control strategy according to neuro-physiological changes due to aging.

When the VSS was applied, some characteristics (i.e. AA_4, HM_2, HP_2, and SM_1) and unexpected parameters (i.e. AM_2, AM_3, AP_2, SM_2, and SM_3) were affected; that is, the function of the hip extensor in the first half of the stance phase, function of the plantar-flexor in the second half of the stance phase, and support moment in the entire stance phase. Consequently, the VSS enhanced motor control of the transition movement in the elderly, and motor control can be regulated depending on the frequency of the VSS as shown in Tables 1, 2, 3 and 4.

These findings suggest that the VSS can be utilized as a means of assisting the transition movement in the elderly. To apply the VSS, various commercial linear actuators can be used. The linear actuator used in the present study was small. Its diameter and thickness were $9 \mathrm{~mm}$ and $3.4 \mathrm{~mm}$, respectively. In addition, to detect the transition movement or any motions, an inertial measurement unit (IMU) device and a device combined with an accelerometer and gyroscope can be used.

There is already a variety of sensors and methodology to detect and recognize human movement. In other words, if the VSS, IMU, power supply, communication module, and regulator for voltage and frequency are combined and miniaturized, the assistance device can be realized. Park et al. [40] and So et al. [41] used inertial sensors to detect gait events and small vibrators to apply somatosensory stimulation, and suggested an algorithm for detecting and stimulating. In addition, portable devices that detect motion and apply stimulation have been used in various clinical studies [42-44]. Therefore, the results of this study can be sufficiently utilized as clinical reference to assist the elderly in their movements, and support the design of assistive devices to enhance motor control by combining the above-mentioned devices and methodologies.

\section{Limitations}

This pilot study has some limitations. 1) the number of participants in this study was small and the sample size between both groups did not the same. 2) the steadystate stair ascent was not investigated in this study. That is, further insight into elders' stair walking, it is required that more sample size and comparing the transition from level walking-to-stair ascending with the steady-state stair ascent.

\section{Conclusion}

The present pilot study showcased the features of the transition from level walking-to-stair ascent in elderly people, and that the VSS may accentuate the features of the transition movement of the elderly. Additionally, it indicated that the frequency of the VSS has the potential to regulate neuromotor controls of the transition.

The results of this study can provide information on the transition movement of the elderly and the references for clinical rehabilitation training to assist and improve their movements. In addition, the observations in this pilot study should be considered when planning future research in the development of motion assistance devices.

\section{Abbreviations}

VSS: Vibrotactile somatosensory stimulus; HA: Hip joint angle; KA: Knee joint angle; AA: Ankle joint angle; HM: Hip joint moment; KM: Knee joint moment; AM: Ankle joint moment; HP: Hip joint power; KP: Knee joint power; AP: Ankle joint power; SM: Support moment; HFM: Hip flexor moment; HEM: Hip extensor moment; KFM: Knee flexor moment; KEM: Knee extensor moment; AEM: Ankle extensor moment; COM: Center of mass; EMG: Electromyography; MEP: Motor evoked potential.

\section{Acknowledgements}

Not applicable.

\section{About this supplement}

This article has been published as part of BMC Musculoskeletal Disorders Volume 22 Supplement 1 2021: Proceedings of the International Conference on Biomedical Engineering Innovation (ICBEI) 2019-2020: musculoskeletal disorders. The full contents of the supplement are available at https://bmcmu sculoskeletdisord.biomedcentral.com/articles/supplements/volume-22-suppl ement-1.

\section{Authors' contributions}

KK performed the experiment, recruited the participants, performed the 3D motion simulation, analyzed all the parameters, participated in the selection criteria and design of the work, drafted the manuscript, edited and revised the manuscript. SK participated in the experiment, and performed the 3D motion simulation. DK supervised the work. All authors read and approved the final manuscript.

\section{Funding}

This work was supported by the National Research Foundation of Korea (NRF) grant funded by the Korea government (MSIT) (NRF-2017R1A2B2009389 and NRF-2019R1A2C2088033), and by Basic Science Research Program through the National Research Foundation of Korea (NRF) funded by the Ministry of Education (NRF-2019R1A6A3A01092848). The funding bodies had no role in the design or conclusions of this study. Publication costs are funded by the National Research Foundation of Korea (NRF) grant funded by the Korea government (MSIT). 


\section{Availability of data and materials}

The datasets used and/or analyzed during the current study are available from the corresponding author on reasonable request.

\section{Declarations}

\section{Ethics approval and consent to participate}

The study "Vibrotactile Somatosensory Stimulus to assist the Transition from Level Walking to Stair ascent in the Elderly" was approved by Jeonbuk National University IRB (IRB File No. JBNU 2017-03-011-001). All participants were informed of the study and gave their informed consent. The consent of the patients was obtained in written form, according to the protocol and the Patient Information Sheet and Informed Consent. All patients were of legal age and none were unconscious.

\section{Consent for publication}

Not applicable.

\section{Competing interests}

The authors declare they have no competing interests.

\section{Author details}

${ }^{1}$ Division of Biomedical Engineering, Jeonbuk National University, 567 Baekje-daero, Deokjin-gu, Jeonju-si, Jeollabuk-do, Republic of Korea. ${ }^{2}$ Department of Healthcare Engineering, Jeonbuk National University, 567 Baekje-daero, Deokjin-gu, Jeonju-si, Jeollabuk-do, Republic of Korea. ${ }^{3}$ Research center for Healthcare \& Welfare Instrument for the Elderly, Jeonbuk National University, 567 Baekje-daero, Deokjin-gu, Jeonju-si, Jeollabuk-do, Republic of Korea.

Received: 3 February 2022 Accepted: 4 February 2022

Published online: 24 February 2022

\section{References}

1. Oh-Park M, Wang C, Verghese J. Stair negotiation time in community dwelling older adults: normative values and association with functional decline. Arch Phys Med Rehabil. 2011;92:2006-11.

2. Nadeau S, McFadyen BJ, Malouin F. Frontal and sagittal plane analyses of the stair climbing task in healthy adults aged over 40 years: what are the challenges compared to level walking? Clin Biomech. 2003;18:950-9.

3. Novak AC, Brouwer B. Sagittal and frontal lower limb joint moments during stair ascent and descent in young and older adults. Gait Posture. 2011;33:54-60.

4. Samuel D, Rowe P, Hood V, Nicol A. The biomechanical functional demand placed on knee and hip muscles of older adults during stair ascent and descent. Gait Posture. 2011;34:239-44.

5. Reeves ND, Spanjaard M, Mohagheghi AA, Baltzopoulos $V$, Maganaris $\mathrm{CN}$. Older adults employ alternative strategies to operate within their maximum capabilities when ascending stairs. J Electromyogr Kinesiol. 2009;19:e57-68.

6. Reeves ND, Spanjaard M, Mohagheghi AA, Baltzopoulos V, Maganaris CN. The demands of stair descent relative to maximum capacities in elderly and young adults. J Electromyogr Kinesiol. 2008;18:218-27.

7. Stacoff A, Diezi C, Luder G, Stüssi E, Kramers-de Quervain IA. Ground reaction forces on stairs: effects of stair inclination and age. Gait Posture. 2005:21:24-38.

8. Larsen AH, Puggaard L, Hämäläinen U, Aagaard P. Comparison of ground reaction forces and antagonist muscle coactivation during stair walking with ageing. J Electromyogr Kinesiol. 2008;18:568-80.

9. Lee HJ, Chou LS. Balance control during stair negotiation in older adults. J Biomech. 2007:40:2530-6

10. Bosse I, Oberländer KD, Savelberg HH, Meijer K, Brüggemann GP, Karamanidis K. Dynamic stability control in younger and older adults during stair descent. Hum Mov Sci. 2012;31:1560-70.

11. Zietz D, Johannsen L, Hollands M. Stepping characteristics and Centre of Mass control during stair descent: effects of age, fall risk and visual factors. Gait Posture. 2011:34:279-84.
12. Lin YC, Fok LA, Schache AG, Pandy MG. Muscle coordination of support, progression and balance during stair ambulation. J Biomech. 2015:48:340-7.

13. Vallabhajosula S, Yentes JM, Momcilovic M, Blanke DJ, Stergiou N. Do lower-extremity joint dynamics change when stair negotiation is initiated with a self-selected comfortable gait speed? Gait Posture. 2012;35:203-8.

14. Vallabhajosula S, Yentes JM, Stergiou N. Frontal joint dynamics when initiating stair ascent from a walk versus a stand. J Biomech. 2012;45:609-13.

15. Singhal K, Kim J, Casebolt J, Lee S, Han KH, Kwo YH. Kinetic comparison of older men and women during walk-to-stair descent transition. Gait Posture. 2014;40:600-4.

16. Alcock L, O'Brien TD, Vanicek N. Biomechanical demands differentiate transitioning vs. continuous stair ascent gait in older women. Clin Biomech. 2004;29:111-8.

17. Carli JVM, Bohrer RCD, Lodovico A, Rodacki ALF. Kinetic analysis of floorto-stair transition gait of elderly with different functional levels. Rev Bras Cineantropom Desempenho Hum. 2014;16:66-75.

18. Eklund G, Hagbarth KE. Normal variability of tonic vibration reflexes in man. Exp Neurol. 1966;16:80-92.

19. Bongiovanni LG, Hagbarth KE. Tonic vibration reflexes elicited during fatigue from maximal voluntary contractions in man. J Physiol. 1990:423:15-26.

20. Lapole T, Perot C. Effects of repeated Achilles tendon vibration on triceps surae force production. J Electromyogr Kinesiol. 2010;20:648-54.

21. Luo J, McNamara B, Moran K. A portable vibrator for muscle performance enhancement by means of direct muscle tendon stimulation. Med Eng Phys. 2005;27:513-22.

22. Luo J, McNamara B, Moran K. The use of vibration training to enhance muscle strength and power. Sports Med. 2005;35:23-41.

23. Alghadir $\mathrm{AH}$, Anwer $\mathrm{S}$, Zafar $\mathrm{H}$, lqbal ZA. Effect of localised vibration on muscle strength in healthy adults: a systematic review. Physiotherapy. 2018;104:18-24.

24. Inavenko YP, Grasso R, Lacquaniti F. Influence of leg muscle vibration on human walking. J Neurophysiol. 2000;84:1737-47.

25. Layne CS, Malaya CA, Levine JT. The effects of muscle vibration on gait control: a review. Somatosens Mot Res. 2019;36:212-22.

26. Murillo N, Valls-sole J, Vidal J, Opisso E, Medina J, Kumru H. Focal vibration in neurorehabilitation. Eur J Phys Rehabil Med. 2014;50:231-42.

27. Annor P, Kwak K, Kim H, Kim D. Effect of local somatosensory stimulus on postural sway during sit-to-stand movement in the elderly. BMC Musculoskelet Disord. 2021;22:1-12.

28. Kwak K, Kim H, Song K, Kim D. Vibration stimulation effect on biomechanical variation of lower-limb joint according to vibration perception threshold. J Vibroeng. 2017;19:3866-74.

29. Kwak K, Kim H, Kim D. A study on the improvement of walking characteristics of the elderly with vibration stimuli applied to the tibialis anterior tendon. Biomed Res Int. 2017. https://doi.org/10.1155/2017/5342485.

30. Kandel ER, Schwartz JH, Jessell TM. Principles of neural science. 4th ed. Seoul: McGraw-Hill Korea, Inc.; 2011.

31. Kim H, Kwak K, Kim D. A study on the effect of vibration stimulation of the sub-perception threshold intensity on lower leg muscle based on the SEPs. J Vibroeng. 2017;19:3019-29.

32. Libet B, Alberts WW, Wright EW, Feinstein B. Responses of human somatosensory cortex to stimuli below threshold for conscious sensation. Science. 1967;158:1597-600.

33. Simeonov P, Hsiao H, Powers J, Ammons D, Kau T, Amendola A. Postural stability effects of random vibration at the feet of construction workers in simulated elevation. Appl Ergon. 2011;42:672-81.

34. Pope MH, Magnusson M, Wilder DG. Kappa Delta award. Lower back pain and whole body vibration. Clin Orthop Relat Res. 1998;354:241-8.

35. Sharif Bidabadi S, Murray I, Lee GYF. Validation of foot pitch angle estimation using inertial measurement unit against marker-based optical 3D motion capture system. Biomed Eng Lett. 2018;8:283-90.

36. Winter DA. Overall principle of lower limb support during stance phase of gait. J Biomech. 1980;13:923-7.

37. Hortobágyi T, Mizelle C, Beam S, DeVita P. Old adults perform activities of daily living near their maximal capabilities. J Gerontol Ser A-Biol Sci Med Sci. 2003:58:M453-60.

38. Hof AL. On the interpretation of the support moment. Gait Posture. 2000;12:196-9. 
39. Steyvers M, Levin O, Verschueren SM, Swinnen SP. Frequency-dependent effects of muscle tendon vibration on corticospinal excitability: a TMS study. Exp Brain Res. 2003;151:9-14.

40. Park MH, Kwak KY, Kim DW. Developing a portable gait cycle detection system using an inertial sensor and evaluating the accuracy of the gait cycle detection. Technol Health Care. 2016;24:S69-76.

41. So HJ, Kim SH, Kim DW. A portable diagnostic and treatment system of abnormal gait using acceleration and gyroscope signal. Appl Mech Mater. 2014:522-524:1133-6.

42. De Nunzio AM, Grasso M, Nardone A, Godi M, Schieppati M. Alternate rhythmic vibratory stimulation of trunk muscles affects walking cadence and velocity in Parkinson's disease. Clin Neurophysiol. 2010;121:240-7.

43. Camerota F, Celletti C, Di Sipio E, Simbolotti C, Germanotta M, Mirabella $M$, et al. Focal muscle vibration, an effective rehabilitative approach in severe gait impairment due to multiple sclerosis. J Neurol Sci. 2017:372:33-9.

44. Pereira MP, Gobbi LTB, Almeida QJ. Freezing of gait in Parkinson's disease: evidence of sensory rather than attentional mechanisms through muscle vibration. Parkinsonism Relat Disord. 2016;29:78-82.

\section{Publisher's Note}

Springer Nature remains neutral with regard to jurisdictional claims in published maps and institutional affiliations.

- fast, convenient online submission

- thorough peer review by experienced researchers in your field

- rapid publication on acceptance

- support for research data, including large and complex data types

- gold Open Access which fosters wider collaboration and increased citations

- maximum visibility for your research: over $100 \mathrm{M}$ website views per year

At BMC, research is always in progress.

Learn more biomedcentral.com/submissions 